\title{
Correction to: Increased DNA Damage and Apoptosis in CDKL5-Deficient Neurons
}

\author{
Manuela Loi ${ }^{1} \cdot$ Stefania Trazzi ${ }^{1} \cdot$ Claudia Fuchs $^{1} \cdot$ Giuseppe Galvani $^{1} \cdot$ Giorgio Medici $^{1} \cdot$ Laura Gennaccaro $^{1}$. \\ Marianna Tassinari ${ }^{1} \cdot$ Elisabetta Ciani $^{1}$ (1)
}

Published online: 17 February 2020

(C) Springer Science+Business Media, LLC, part of Springer Nature 2020

\section{Correction to: Mol Neurobiol}

https://doi.org/10.1007/s12035-020-01884-8

The original version of this article unfortunately contained error in Fig. 5a to where a panel is missing.

The correct Fig. 5a is hereby published.

The original article has been corrected.

Publisher's Note Springer Nature remains neutral with regard to jurisdictional claims in published maps and institutional affiliations.

The online version of the original article can be found at https://doi.org/ 10.1007/s12035-020-01884-8

Stefania Trazzi

stefania.trazzi3@unibo.it

$\triangle$ Elisabetta Ciani

elisabetta.ciani@unibo.it

1 Department of Biomedical and Neuromotor Sciences, University of Bologna, Piazza di Porta San Donato 2, 40126 Bologna, Italy 

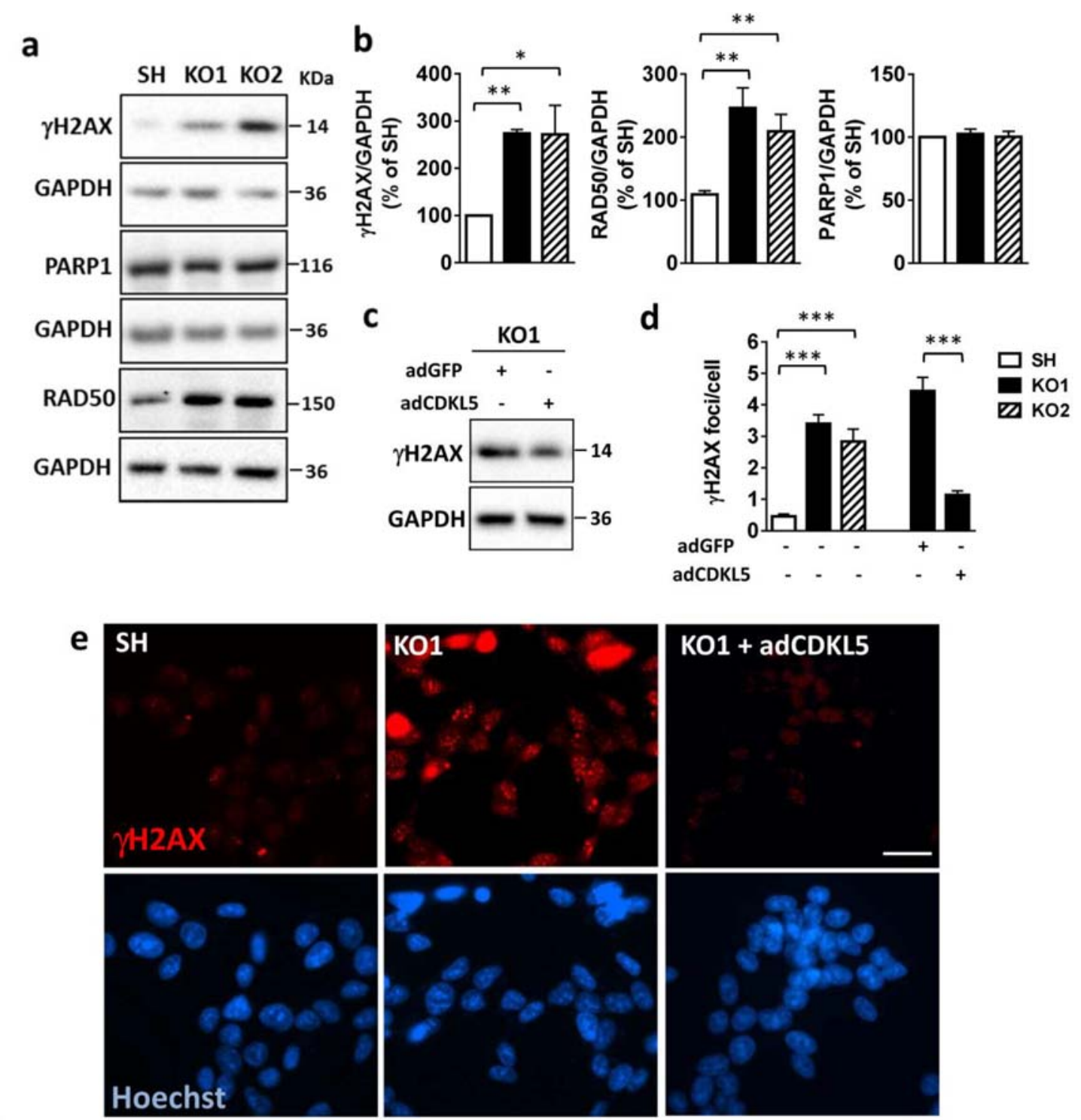

f
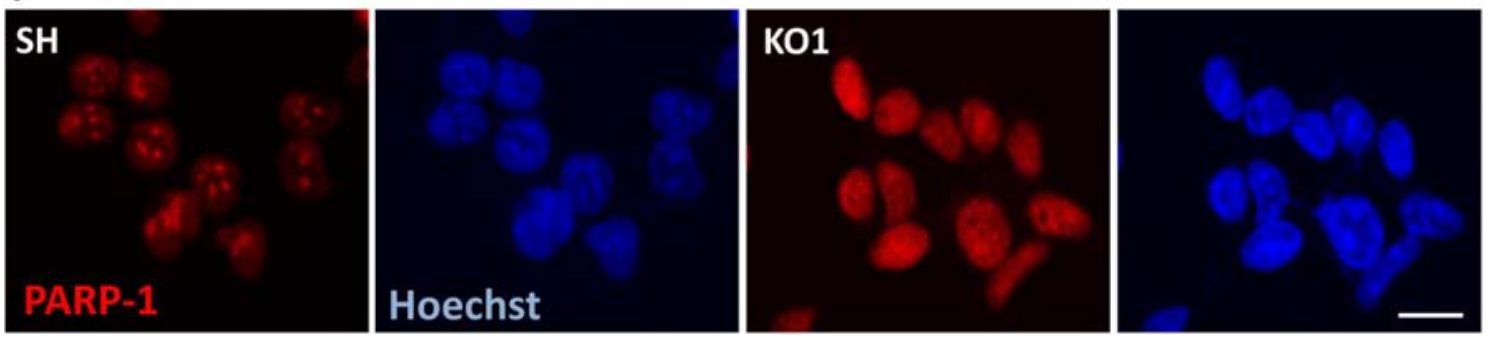